\title{
Effect of Mn Element Addition on the Microstructure, Mechanical Properties, and Corrosion Properties of Mg-3Zn-0.2Ca Alloy
}

\author{
Yu Yan Han ${ }^{1}$, Chen You ${ }^{1,2 *}$, Yun Zhao ${ }^{1,2,3}$, Min Fang Chen ${ }^{1,2,3 *}$ and Liang Wang ${ }^{1}$ \\ ${ }^{1}$ School of Materials Science and Engineering, Tianjin University of Technology, Tianjin, China, ${ }^{2}$ Key Laboratory of Display \\ Materials and Photoelectric Device, Ministry of Education, Tianjin, China, ${ }^{3}$ Tianjin Key Laboratory for Photoelectric Materials \\ and Devices, Tianjin, China
}

OPEN ACCESS

Edited by:

Hajo Dieringa,

Helmholtz Centre for Materials and

Coastal Research (HZG), Germany

Reviewed by:

Jiangfeng Song,

Chongqing University, China

Sinan Kandemir,

Izmir Institute of Technology, Turkey

*Correspondence:

Chen You

youchentj@126.com

Min Fang Chen

mfchentj@126.com

Specialty section:

This article was submitted to

Structural Materials,

a section of the journal

Frontiers in Materials

Received: 22 May 2019 Accepted: 25 November 2019 Published: 10 December 2019

Citation:

Han YY, You C, Zhao Y, Chen MF and Wang L (2019) Effect of Mn Element

Addition on the Microstructure, Mechanical Properties, and Corrosion

Properties of Mg-3Zn-0.2Ca Alloy.

Front. Mater. 6:324.

doi: 10.3389/fmats.2019.00324
Magnesium-zinc-calcium alloys have unique advantages of being used as biomedical bone implants since their mechanical properties and biocompatibility are similar to human tissues. However, insufficient strength and poor corrosion resistance have been the major problems to stunt the application. In this paper, the changes of microstructure, mechanical properties and corrosion resistance of ternary Mg-3Zn-0.2Ca (wt.\%) with different contents of $\mathrm{Mn}(0.3,0.5,0.7,0.9$, wt.\%) are studied. With the increase of Mn content, the grain size of as-cast alloy first decreases and then increases, this indicates that the amount of $\mathrm{Mn}$ affects the degree of subcooling of the alloy. At the $320^{\circ} \mathrm{C} / 24 \mathrm{~h}$ homogenizing treatment, the large and uneven dendrites are transformed into uniform equiaxed grains, the mechanical properties of alloys with different $\mathrm{Mn}$ contents are different on the basis of Mg-3Zn-0.2Ca (wt.\%) alloy. The five alloys were extruded into bar with a diameter of $8 \mathrm{~mm}$ through hot-extrusion process. Quaternary Mg-3Zn-0.2Ca-XMn $(X=0.3,0.5,0.7,0.9)$ (wt.\%) alloys are investigated and the results show that 0.5 wt.\% Mn alloy has the best yield tensile strength (YS) (302 MPa) and good ultimate tensile strength (UTS) (327 MPa). The reason is that the different contents of $\mathrm{Mn}$ restrain the dynamic recrystallization in extrusion process, which remarkedly reduced the grain size. Moreover, each alloy is investigated by electrochemical measurements at $37^{\circ} \mathrm{C}$ in a simulated body fluid (SBF). The electrochemical results show that the corrosion potential of Mn-contained alloys are increased compared to ternary Mg-3Zn-0.2Ca (wt.\%) alloy, and 0.5 wt. $\%$ Mn-contained alloy performs the best result.

Keywords: biomedical magnesium alloys, microstructure, mechanical properties, corrosion properties, $\alpha$-Mn

\section{INTRODUCTION}

With the advancement of medical science and technology, metal implants have become an indispensable technical means in clinical medicine as an important part of bone reconstruction surgery. Some studies have shown that the use of metal implants in clinical bone reconstruction surgery has significantly improved the cure rate of large femoral fractures and bone injuries (Prins et al., 2018; Han et al., 2019).

Metal implants complete the healing process by setting the skeleton in place (Ibrahim et al., 2017). Currently, metal implant materials widely used in medicine mainly include titanium 
alloys, CoCr alloys and stainless steels, which cannot be absorbed by themselves and need to be permanently retained in the body or removed by secondary surgery. Permanent retention in the body will produce stress shielding after the completion of bone healing, and secondary removal will make the patient suffer from the pain of surgery again and lead to complications (Best et al., 2008; Lutz and Mändl, 2010; Arifin et al., 2014; Ibrahim et al., 2017). Therefore, we hope that there can be a material that gives sufficient strength and stiffness support during bone healing. Once the bone tissue heals, it begins to degrade and be absorbed in the body (Ibrahim et al., 2017). Magnesium and its alloys not only show excellent biocompatibility and similar mechanical properties of human bones, but also can be degraded and absorbed in the body without secondary surgery, which has received widespread attention from the scientific and medical community (Kannan and Raman, 2008; Zheng et al., 2014; Witte, 2015; Jin et al., 2019). However, owing to the insufficient mechanical properties and the rapid degradation rate, magnesium alloys have limited their applications in the medical industry (Yin et al., 2013; Tian and Liu, 2015; Bian et al., 2017). Generally, the period of bone remodeling is 3-6 months, and thus improving the mechanical properties and corrosion resistance of magnesium alloys as well as ensuring their effective service have become the focus of our current research.

Previous studies usually reported the usage of alloying or microalloying to modify the microstructures and sediments to improve their comprehensive properties. In the current studies, the main alloying elements are $\mathrm{Ca}, \mathrm{Sr}, \mathrm{Zn}, \mathrm{Si}, \mathrm{Mn}, \mathrm{Li}, \mathrm{Zr}, \mathrm{Nd}$, Y, RE, Al (Gu et al., 2012; Li and Zheng, 2013; Yin et al., 2013; Zhou et al., 2013; Seong and Kim, 2015; Tian and Liu, 2015; Yandong et al., 2015; Cho et al., 2016; Bian et al., 2017; Gil-Santos et al., 2017; Jiang et al., 2017; Gui et al., 2018; Abdel-Gawad and Shoeib, 2019; Guo et al., 2019; Jin et al., 2019; Liao et al., 2019; Lou et al., 2019). Based on the biosafety to the human body, the biological functional elements $\mathrm{Ca}, \mathrm{Sr}$, and the essential trace elements $\mathrm{Zn}, \mathrm{Si}, \mathrm{Mn}$ can be as the main alloying elements. $\mathrm{Ca}$ is the main component of human bones, which is essential for chemical signal transduction in cells. The released ions of $\mathrm{Ca}$ as a mineral nutrient are beneficial to bone solidification (Harkness and Darrah, 2019). Du et al. (2016) found that the addition of $\mathrm{Ca}$ to the $\mathrm{Mg}$-6Zn alloy inhibited dynamic recrystallization and grain growth during extrusion. Meanwhile, the sediments of the alloy deposited are also increased and the alloy strength was raised by $84 \%$. Yin et al. (2013) found that the addition of $\mathrm{Ca}$ into the $\mathrm{Mg}-5 \mathrm{Zn}$ alloy was beneficial to grain refinement. The mechanical properties and biocorrosion properties of the alloy were significantly improved. High $\mathrm{Ca}$ would lead to good mechanical properties and low corrosion resistance and $\mathrm{Mg}-5 \mathrm{Zn}-1.0 \mathrm{Ca}$ exhibited excellent corrosion resistance and good biocompatibility. Another element, Zinc, is the most common and basic nutrient element in human body. It plays an extremely important role in important physiological processes such as human growth and development, reproductive genetics, immunity, and endocrine. Zhang et al. (2011) studied the effects of different zinc contents on the mechanical, corrosion and cytotoxicity of $\mathrm{Mg}-\mathrm{Zn}-\mathrm{Ca}$ alloys. It was found that the tensile strength and corrosion rate first increased and then decreased with the increase of $\mathrm{Zn}$ content. When the composition is $<3$ wt.\% $\mathrm{Zn}$, the component alloy is non-toxic. $\mathrm{Mn}$ is a basic element of the human body and can be accepted by the human body. Some reports (Jiang et al., 2016; Ibrahim et al., 2017) indicate that $\mathrm{Mn}$ element can refine grains by inhibiting recrystallization growth during alloy extrusion. Further, Mn element can also be combined with impurity elements during the smelting process to form a high melting point compound precipitated at the bottom of the melt to purifying the alloy. He et al. (2018) investigated the in vitro corrosion and biocompatibility of extruded $\mathrm{Mg}-6 \mathrm{Zn}$ $\mathrm{Mn}$ alloy and found that the corrosion rate of extruded alloy was only $1.01 \pm 0.10 \mathrm{~mm} /$ year after simulated body fluid (SBF) soaking for 1 month, and the cells were non-toxic. Yandong et al. (2015) studied the effects of different Mn compositions on the microstructure and mechanical properties of $\mathrm{Mg}-\mathrm{Zn}-$ $\mathrm{Ca}$ alloys. It was found that the strength and elongation of ascast and heat-treated alloys decreased with the increase of $\mathrm{Mn}$ content. The optimum tensile strength of heat-treated $\mathrm{Mg}-2 \mathrm{Zn}$ $0.5 \mathrm{Ca}-1.0 \mathrm{Mn}$ alloy is $205 \mathrm{MPa}$ and the elongation is $15.7 \%$. Cho et al. (2017) found that the addition of Mn has an obvious grain refining effect on $\mathrm{Mg}-4 \mathrm{Zn}-0.5 \mathrm{Ca}$ alloy, which greatly improved the comprehensive performance of magnesium alloy. Previous studies on alloying element Mn have been reported, but the results are different, and the mechanical properties and corrosion resistance are still relatively low. Therefore, more studies are needed to fully understand the effect of $\mathrm{Mn}$ on magnesium alloys.

In this work, based on the previous research reports (Lin et al., 2018a,b), this work mainly focused on the effects $\mathrm{Mn}$ with different contents in ternary $\mathrm{Mg}-3 \mathrm{Zn}-0.2 \mathrm{Ca}$ alloy, and the microstructure, mechanical properties and corrosion properties are investigated systematically, which provide a more reliable basis for the further development of biomedical magnesium alloys by optimizing $\mathrm{Mn}$ content to enhance mechanical properties and corrosion performance of biomedical magnesium alloys.

\section{EXPERIMENTAL MATERIALS AND METHODS}

\section{Material Preparation}

Pure magnesium ingot (99.99 wt.\%), pure zinc particles (99.99 wt.\%), Mg-Ca master alloy (with 25 wt.\% Ca), and $\mathrm{Mg}$ $\mathrm{Mn}$ master (with 10 wt.\% Mn) alloy were used to make Mg-3Zn-0.2Ca (wt.\%) (MZC), Mg-3Zn-0.2Ca-0.3Mn (wt.\%) (MZC0.3Mn), Mg-3Zn-0.2Ca-0.5Mn (wt.\%) (MZC0.5Mn), Mg$3 \mathrm{Zn}-0.2 \mathrm{Ca}-0.7 \mathrm{Mn}$ (wt.\%) (MZC0.7Mn), and Mg-3Zn-0.2Ca$0.9 \mathrm{Mn}$ (wt.\%) (MZC0.9Mn) alloys. In the process of cultivating, all of alloys used vacuum induction furnace under the protection of argon atmosphere gas for melting and casting. The furnace is first heated to $720^{\circ} \mathrm{C}$, then stirred for 2-3 min, kept warm for 2-3 min, cut off the power and started casting at a constant speed until the temperature drops to $690^{\circ} \mathrm{C}$. The five alloy ingots were homogenized separately to eliminate dendrites, and then extruded at $315^{\circ} \mathrm{C}$ on a hot-extrusion molding machine. During the extrusion, the speed is set to $2-4 \mathrm{~mm} / \mathrm{s}$. 


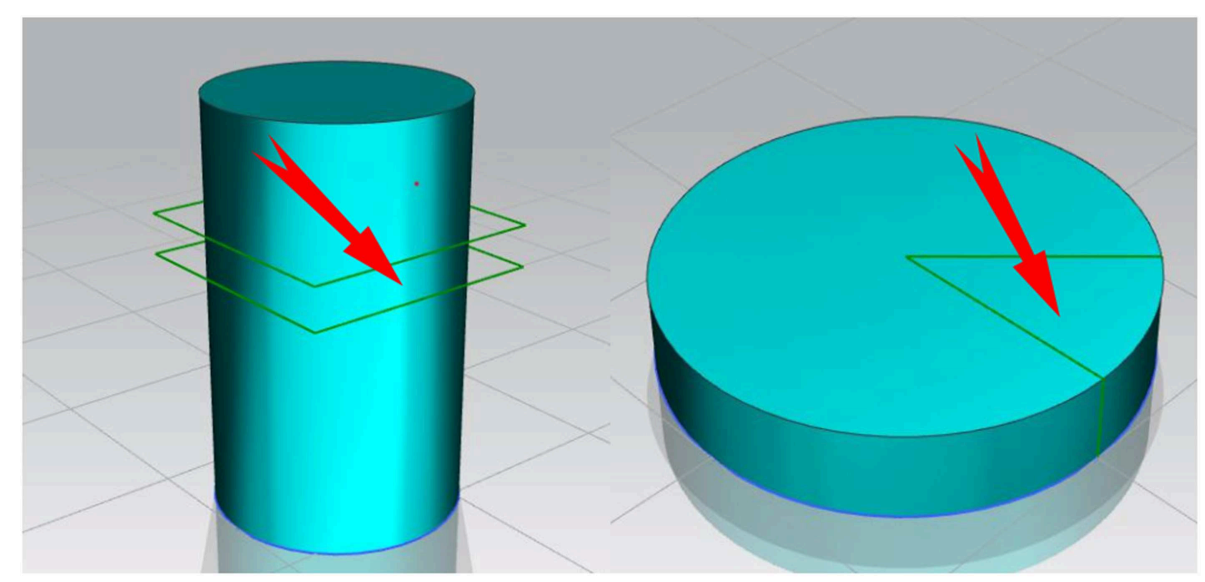

FIGURE 1 | The selected position of samples for microstructures observation.

\section{Selection of Specimens and Observation of Microstructure}

Microstructures of the as-cast alloys and homogenized alloys were observed by optical microscope (OM) and scanning electron microscopy (SEM), respectively. The grain size of five alloys are determined by GB/T 6394-2002 standards. The second phase particle size in the homogenized alloys is calculated by using the SEM ruler. Five different alloy samples must be selected at the same height and the same position for comparison. The selected position is shown in Figure 1.

\section{X-Ray Diffraction and EDS Analysis}

The phase composition of the detected phase was measured by $\mathrm{X}$-ray diffraction at a scanning speed of $10 \mathrm{~min}$, an acceleration voltage of $40 \mathrm{kV}$, a current of $100 \mathrm{~mA}$ and a $\mathrm{Cu}$ target $\mathrm{K} \alpha$ radiation $(\lambda=0.141618 \mathrm{~nm}$ ). Analysis was performed by using JADE5 software to determine the presence of the second phase in the sample. The second phase in the alloy is determined by using EDS.

\section{Mechanical Properties Test}

Tensile test is carried out by using an electronic universal testing machine at room temperature. The tensile test specimens are machined according to GB/T 16865-2013 standards. The test speed is set to $0.5 \mathrm{~mm} / \mathrm{min}$. Three parallel samples are set in each group and the fracture morphology of failed specimens is analyzed by SEM.

\section{Electrochemical Experiment}

The electrochemical polarization and impedance experiments were carried out in a simulated body fluid (SBF) at $37^{\circ} \mathrm{C}$ by using a Zennium electrochemical workstation. The sample was used as the working electrode, graphite as the counter electrode and saturated calomel as the reference electrode to form a threeelectrode assembly. Each surface exposed to the sample was smoothed by 3,000 grit water sandpaper and immersed in $37^{\circ} \mathrm{C}$ SBF for $30 \mathrm{~min}$ before the test. Three parallel samples were set in each group to ensure the accuracy. The polarization resistance
(Rp) of the samples to be tested are calculated by using Equation (1) (Bakhsheshi-Rad et al., 2012).

$$
R_{P}=\frac{\beta \alpha \beta c}{2.303(\beta \alpha+\beta c) I \text { corr }}
$$

In the Equation (1), $\beta$ c represents the cathode Tafel slope, $\beta \alpha$ represents the anode Tafel slope, and Icorr represents the corrosion current density, respectively.

\section{RESULTS AND DISCUSSION}

\section{Microstructure Observation}

The microstructures of as-cast MZC, MZC0.3Mn, MZC0.5Mn, MZC0.7Mn, and MZC0.9Mn alloys are shown in Figure 2. Compared with the five alloys, it can be found that the addition of Mn element changed the overall solute distribution of the alloy matrix. The ellipsoidal precipitates increase and evenly disperse in the rich Mn-contained alloys. A large number of second phases are also accumulated at the grain boundaries. The morphology and distribution of these second phases may affect the subsequent mechanical properties and corrosion resistance.

The average grain sizes of as-cast MZC, MZC0.3Mn, MZC0.5Mn, MZC0.7Mn, and MZC0.9Mn alloys are shown in Figure 3. The average grain size of the five alloys first decreases and then increases, and the MZC0.5Mn alloy has the smallest grain size $(74.2 \pm 10.1 \mu \mathrm{m})$. The reason may be that with the addition of Mn element, the solute at the S/L interface aggregates, causing different degrees of structural overcooling. In previous reports, the effect of the addition of $\mathrm{Mn}$ on the supercooling of magnesium alloys was also confirmed (Cho et al., 2017).

In order to eliminate dendrites, five alloys are homogenized and the SEM photographs of five alloys are shown in Figure 4. Compared with the MZC alloy, the ellipsoidal second phase and elongated second phase at the grain boundary of Mn-contained alloys are significantly increased. Figure $4 \mathrm{~F}$ shows the EDS data of the ellipsoidal second phase. It can be seen that the atomic ratio $\mathrm{Mg}: \mathrm{Zn}: \mathrm{Ca}$ is closed to $6: 3: 2$, and the ellipsoidal second phase can 


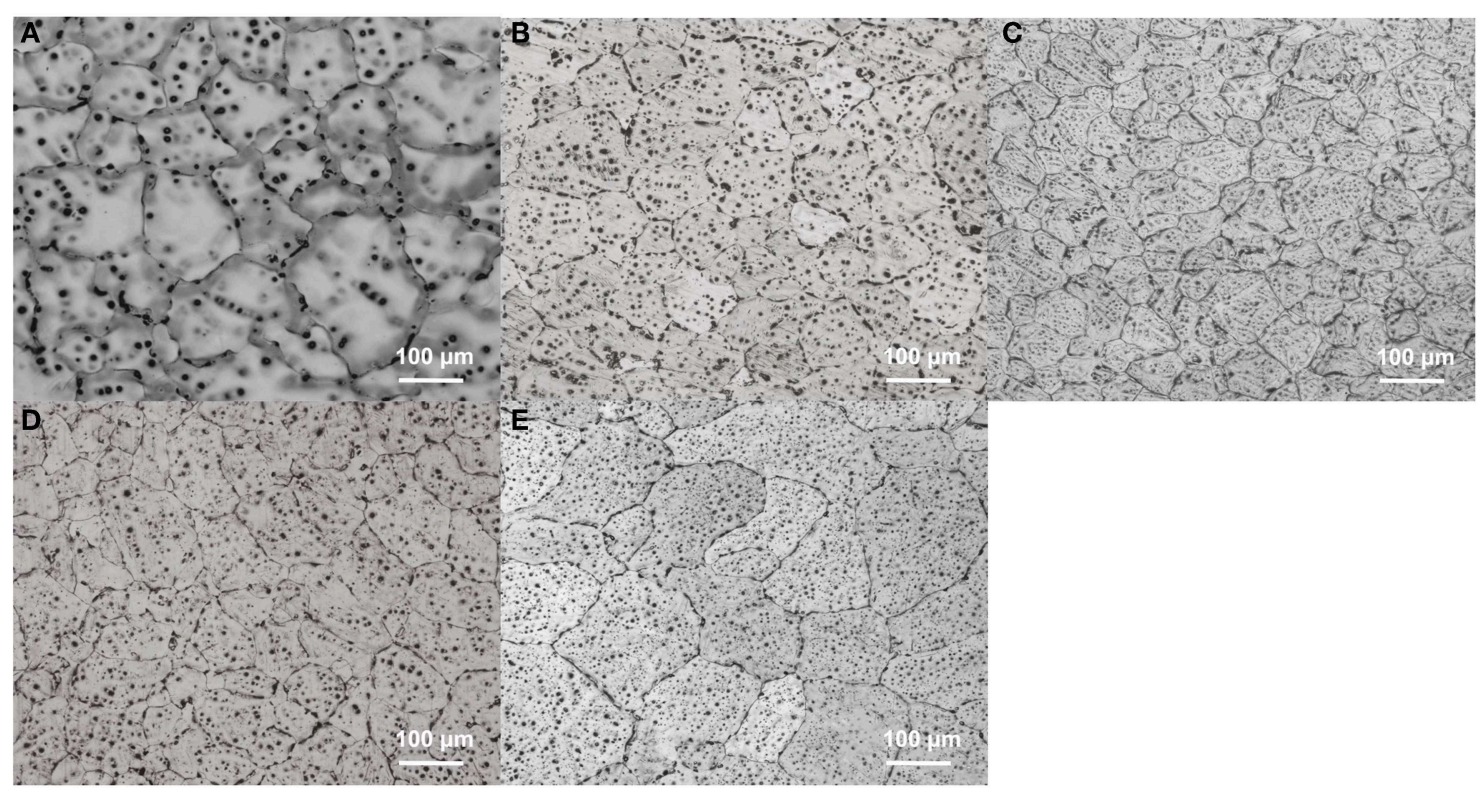

FIGURE 2 | Optical images of as-cast MZC (A), MZC0.3Mn (B), MZC0.5Mn (C), MZC0.7Mn (D), and MZC0.9Mn (E) alloys.

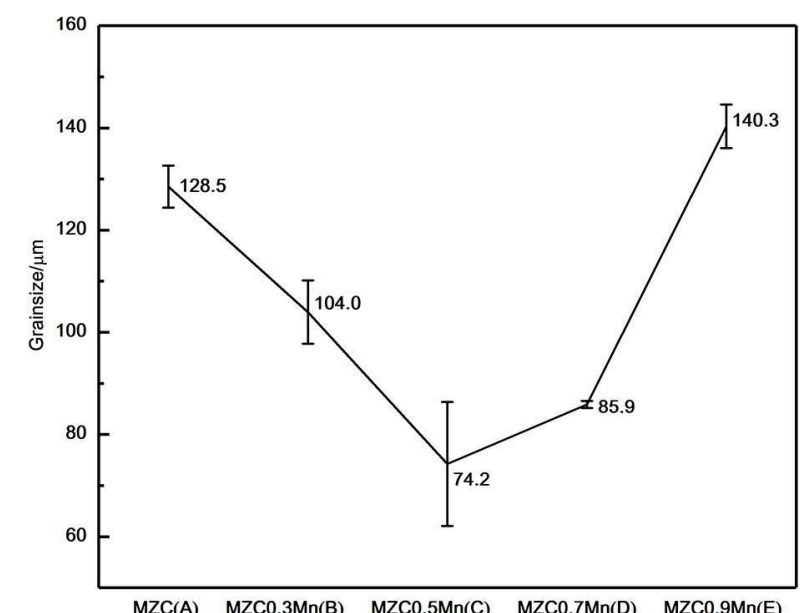

FIGURE 3 | The grain size of as-cast MZC (A), MZC0.3Mn (B), MZC0.5Mn (C), MZC0.7Mn (D) and MZCo.9 Mn (E) alloys.

be inferred to be $\mathrm{Ca}_{2} \mathrm{Mg}_{6} \mathrm{Zn}_{3}$ phase (Bakhsheshi-Rad et al., 2012). Previous studies (Oh-ishi et al., 2009) have shown that the long strip-shaped second phase at the grain boundary of the ternary $\mathrm{Mg}-\mathrm{Zn}$-Ca alloy is mainly $\mathrm{Ca}_{2} \mathrm{Mg}_{6} \mathrm{Zn}_{3}$ phase. Therefore, it can conclude that the addition of $\mathrm{Mn}$ element greatly promotes the precipitation of the ternary $\mathrm{Ca}_{2} \mathrm{Mg}_{6} \mathrm{Zn}_{3}$ phase.

It is also found that the difference in the content of Mn has a certain influence on the distribution of the second phase and the size of the second phase in the SEM photograph. The ellipsoidal second phase particle size measured by SEM scale is shown in Figure 5. The ellipsoidal second phase of MZC0.5Mn alloy is the smallest and the dispersion is more uniform.
SEM photographs of as-extruded MZC, MZC0.3Mn, MZC0.5Mn, MZC0.7Mn, and MZC0.9Mn alloys are shown in Figure 6. The average grain sizes of the five alloys measured by SEM scale are $3.2 \pm 0.30,3.0 \pm 0.63,1.5 \pm 0.43,2.0 \pm$ 0.06 , and $1.9 \pm 0.59 \mu \mathrm{m}$, respectively. The Mn-contained alloys after hot extrusion deformation have smaller grain sizes compared to the MZC alloy. This may be due to the fact that the $\alpha-\mathrm{Mn}$ particles dynamically precipitated during the extrusion process, inhibiting the grain growth of the alloy, resulting in a decrease in the grain size of the Mn-containing alloy (Jiang et al., 2016). It can also be seen from the SEM photographs that the volume of the second phase of the Mncontained alloys are significantly increased compared to the MZC alloy.

Figure 7 shows the as-extruded $\mathrm{X}$-ray diffraction patterns of MZC, MZC0.3Mn, MZC0.5Mn, MZC0.7Mn, and MZC0.9Mn alloys. The as-extruded MZC alloy mainly consists of $\alpha-\mathrm{Mg}$, $\mathrm{MgZn}_{2} \mathrm{Mg}_{2} \mathrm{Ca}$, and $\mathrm{Ca}_{2} \mathrm{Mg}_{6} \mathrm{Zn}_{3}$. Compared with MZC alloy, the amount of $\mathrm{Ca}_{2} \mathrm{Mg}_{6} \mathrm{Zn}_{3}$ in $\mathrm{Mn}$-contained alloys are increased significantly. Meanwhile, the amount of $\mathrm{Mg}_{2} \mathrm{Ca}$ in $\mathrm{Mn}$-contained alloys are decreased. This is probably due to the Mn element which changes the solute element distribution and causes the solute atoms $\mathrm{Zn}$ and $\mathrm{Ca}$ to aggregate in a certain region to form more ternary phase $\mathrm{Ca}_{2} \mathrm{Mg}_{6} \mathrm{Zn}_{3}$. In Mn-contained alloys, the $\mathrm{Mn}$ exists in the form of a simple substance of $\mathrm{Mn}$ and an $\alpha$-Mn phase, and does not form a second phase with other elements.

It is also found in XRD diffraction patterns that the three strong peaks of $\mathrm{Mg}$ of $\mathrm{Mn}$-contained alloys have a small amount of left bias at the basis of MZC alloy. MZC0.9Mn alloy has the largest offset angle, which is approximately $0.1^{\circ}$. This may be due to the lattice distortion caused by $\mathrm{Mn}$ entering the gap of $\mathrm{Mg}$ (HCP) cells. 


\section{HV: 15kv; mag:1000x;det:ETD;mode:SE;VAC mode:High Vacuucm}
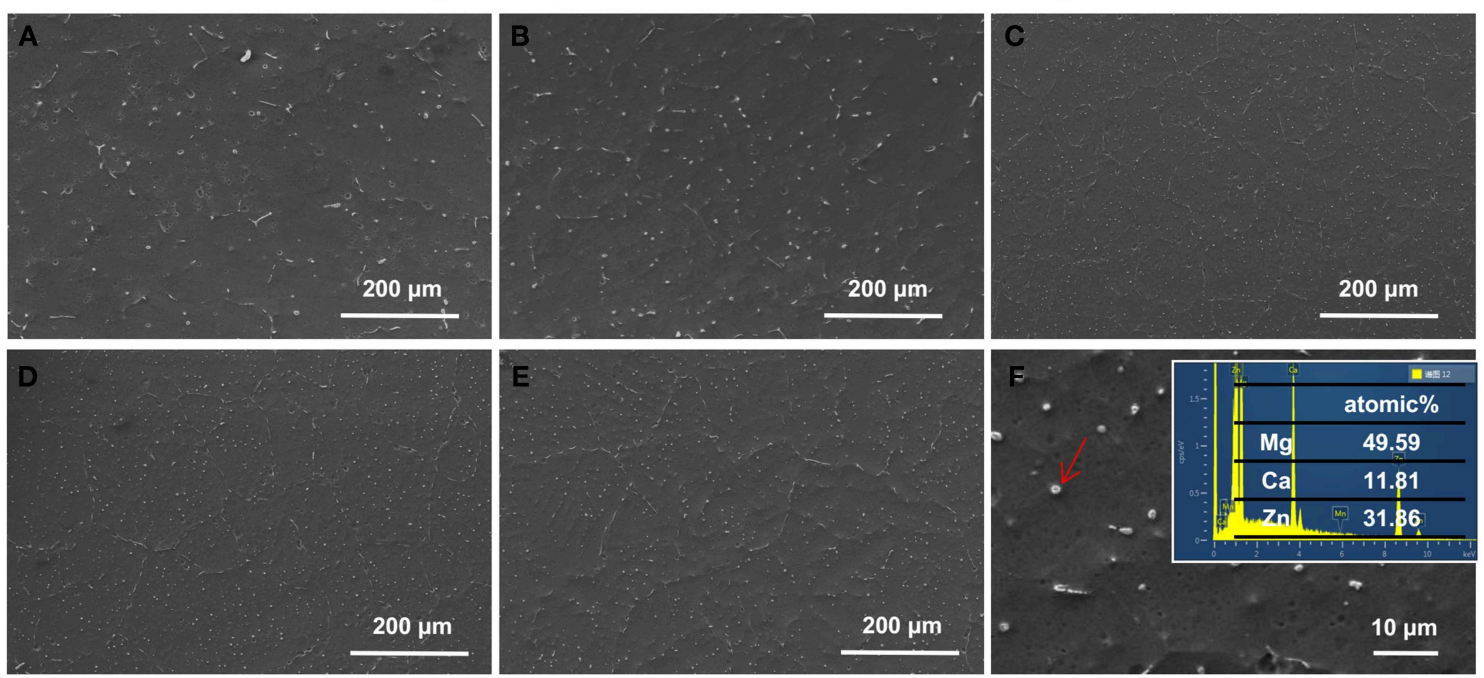

FIGURE 4 | The field-emission scanning images of as-cast homogenization MZC (A), MZC0.3Mn (B), MZC0.5 Mn (C), MZC0.7Mn (D), and MZC0.9Mn (E) alloys and the EDS image of ellipsoidal second phase (F)

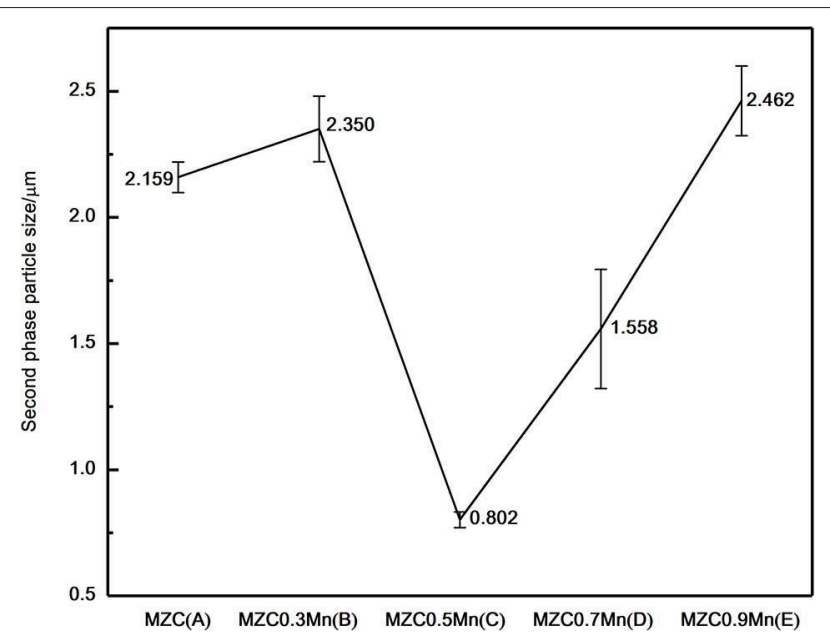

FIGURE 5 | Average particle size of spherical second phase measured by using SEM scale. (A) MZC, (B) MZC0.3Mn, (C) MZC0.5Mn, (D) MZC0.7Mn, and (E) MZC0.9 Mn.

\section{Mechanical Properties Analysis}

Figure 8 displays the tensile stress-strain curves of as-extruded MZC, MZC0.3Mn, MZC0.5Mn, MZC0.7Mn, and MZC0.9Mn alloys and the local stress-strain amplification curve of the MZC alloy. Table 1 lists the room temperature mechanical properties of the five alloys. It can be seen that the MZC0.5Mn alloy exhibits the best mechanical properties. Compared with MZC alloy, the yield strength and tensile strength of MZC0.5Mn alloy are increased by 25.1 and $3.1 \%$, respectively, and the elongation is not significantly reduced. The MZC $0.5 \mathrm{Mn}$ alloy has the best grain refining effect, its second phase is finely dispersed and evenly distributed, and consequently the dispersion strengthening and dislocation pinning effect are obvious. Among this five alloys, MZC0.3Mn alloy has the worst mechanical properties. This is attributed to the fact that the addition of $0.3 \mathrm{wt} \% \mathrm{Mn}$ element increases the $\mathrm{Ca}_{2} \mathrm{Mg}_{6} \mathrm{Zn}_{3}$ phase while the grains are not significantly refined, and the coarse brittle phase $\mathrm{Ca}_{2} \mathrm{Mg}_{6} \mathrm{Zn}_{3}$ is unevenly distributed, which further exacerbates the yield and fracture of the sample.

The fracture surfaces of MZC and Mn-contained alloys are further analyzed to verify the effect of $\mathrm{Mn}$ on the mechanical properties of MZC alloy. The fracture morphologies of five alloys are shown in Figure 9. In the fracture morphology, the observation and analysis are carried out from four aspects: the macroscopic orientation of the section, the macroscopic morphology, fracture path and fracture morphology.

Macroscopic fractures of as-extruded MZC and Mncontained alloy samples are observed with the naked eye. It can be seen that fractures are dark gray fibers with a little fine crystalline particles. It preliminarily demonstrates that the fractures are mostly ductile fracture with a small part of quasicleavage fracture. The SEM photographs of the fracture macro morphology of five as-extruded alloys are shown in Figures A1E2. It can be seen in Figures 9A1-E1 that the fracture section direction is at an angle of $\sim 45$ degrees with the normal stress direction, which is consistent with the direction of the maximum shear stress and corresponding to the characteristics of shear slip fracture. The typical three-zone characteristics of the ductile fracture (fiber zone, radiation zone, shear lip zone) of five alloys can be seen in Figures 9A2-E2. MZC alloy has the most obvious characteristics of the three zones and performs the best toughness.

The fracture micro morphology of five as-extruded alloys SEM photographs are shown in Figures 9A3-E5. It is apparent in the Figures $\mathbf{9 A 3}-\mathbf{E 3}$ that the cleavage step and tearing ridge 
HV: 10KV; mag;2000x; det: ETD; mode: SE; vac mode: High Vacuum
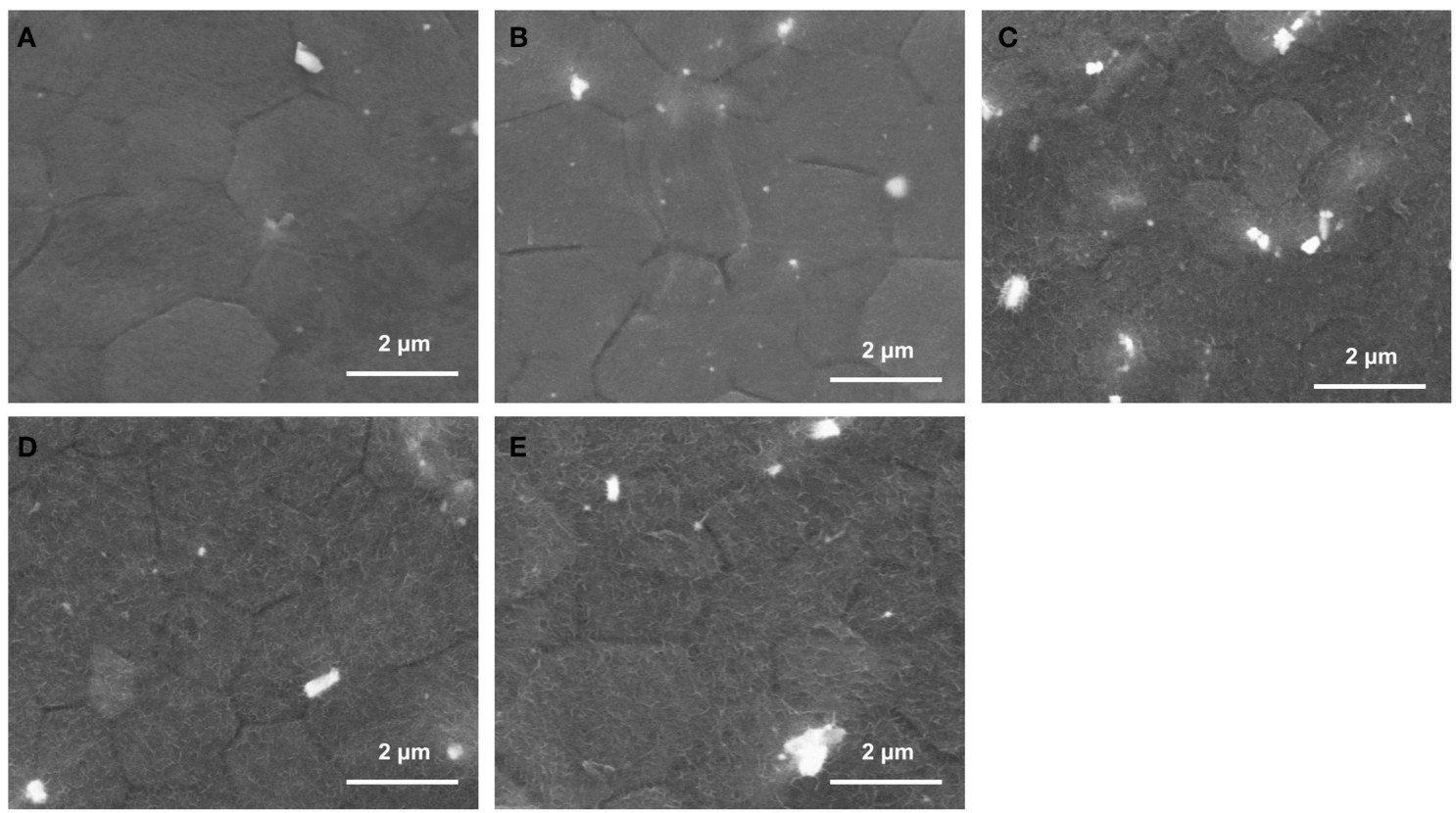

FIGURE 6 | The field-emission scanning images of as-extruded MZC (A), MZCO.3Mn (B), MZC0.5Mn (C), MZC0.7 Mn (D), and MZC0.9 Mn (E) alloys.

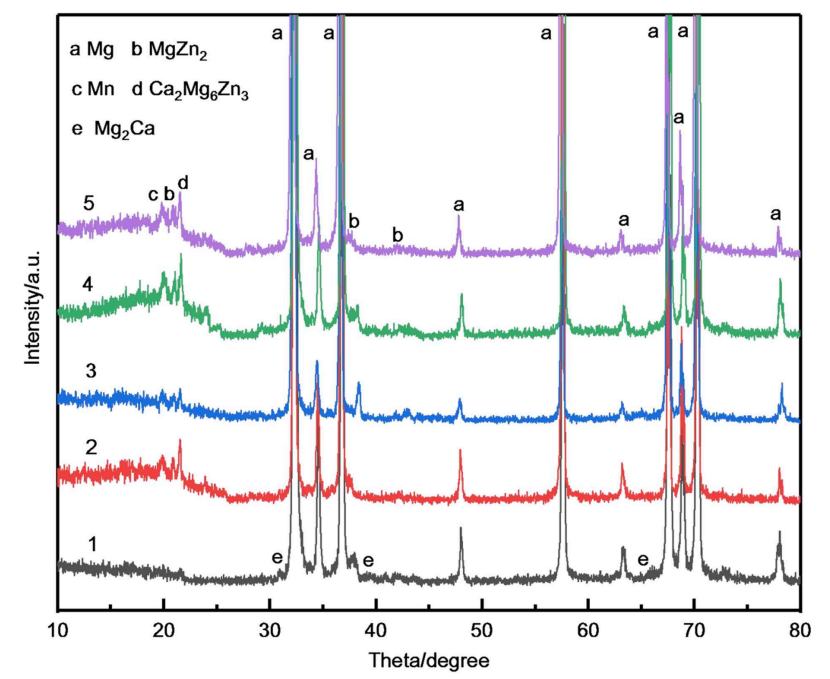

FIGURE 7 | The XRD patterns of as-extruded MZC (1), MZCO.3Mn (2), MZC0.5 Mn (3),MZC0.7Mn (4) and MZC0.9 Mn (5) alloys.

are more pronounced in Mn-contained alloys than the MZC alloy. Figures 9A4-E5 show a large number of dimples that contain obvious second phase particles, mainly corresponding to microporous aggregate fracture. From the analysis of the fracture path, it can be seen from the Figures 9A3-E5 that the five alloys contain both transgranular and intergranular fractures. In addition, it can be clearly seen from the Figures $9 B 4,5$ that the

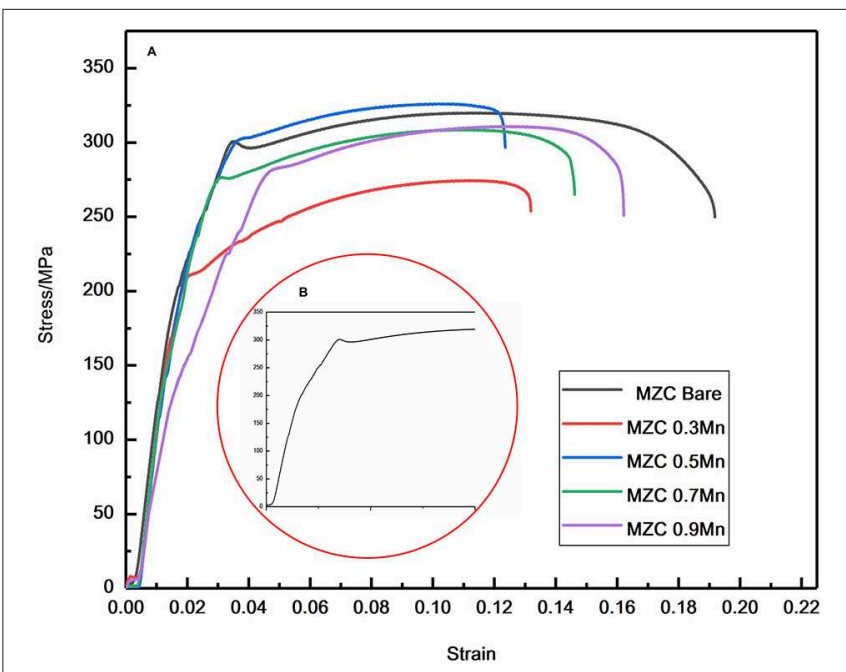

FIGURE 8 | Tensile stress-strain curve of as-extruded MZC, MZC0.3Mn, MZC0.5Mn, MZC0.7Mn and MZC0.9Mn alloys (A) and Local region of tensile stress-strain curve of as-extruded MZC alloy (B).

quasi-cleavage fracture of MZC0.3Mn alloy is most prominent and severe, and thus exhibits poor toughness. The above fracture analysis is consistent with the tensile test results.

\section{Electrochemical Properties Analysis}

Figure 10 shows the electrochemical polarization curves of as-extruded MZC, MZC0.3Mn, MZC0.5Mn, MZC0.7Mn, 
and MZC0.9Mn alloys. The corrosion current densities of the five alloys are obtained by Tafel extrapolation based on the polarization curve. The specific data is shown in Table 2.

Figure 10 indicates that the MZC0.3Mn, MZC $0.5 \mathrm{Mn}$, MZC0.7Mn, and MZC0.9Mn alloys have a longer yield plateau compared to the MZC alloy, which means that a more dense passivation film is formed on the surface of the alloys with $\mathrm{Mn}$ than the surface of the control when the sample is

TABLE 1 | Mechanical properties of as-extruded MZC, MZC0.3Mn, MZC0.5Mn, $\mathrm{MZCO} .7 \mathrm{Mn}$, and MZCO.9Mn alloys.

\begin{tabular}{lccc}
\hline Samples & YS (MPa) & UTS (MPa) & EL (\%) \\
\hline MZC & $241.709 \pm 3.22$ & $317.793 \pm 2.75$ & $15.75 \pm 1.24$ \\
MZC0.3Mn & $210.879 \pm 5.37$ & $274.251 \pm 0.22$ & $14.14 \pm 0.95$ \\
MZC0.5Mn & $302.348 \pm 2.35$ & $327.572 \pm 0.80$ & $13.92 \pm 1.6$ \\
MZC0.7Mn & $275.226 \pm 2.66$ & $314.324 \pm 1.53$ & $15.736 \pm 0.67$ \\
MZC0.9Mn & $245.767 \pm 6.49$ & $312.217 \pm 2.63$ & $14.676 \pm 1.33$
\end{tabular}

immersed in the SBF. The previous XRD diffraction pattern shows that the MZC alloy is mainly composed of $\alpha-\mathrm{Mg}$, $\mathrm{MgZn}_{2}, \mathrm{Mg}_{2} \mathrm{Ca}$ and $\mathrm{Ca}_{2} \mathrm{Mg}_{6} \mathrm{Zn}_{3}$ phases. The addition of $\mathrm{Mn}$ increases the precipitation of $\mathrm{Ca}_{2} \mathrm{Mg}_{6} \mathrm{Zn}_{3}$ while reduces the phase of $\mathrm{Mg}_{2} \mathrm{Ca}$. The addition of $\mathrm{Mn}$ inhibits the grain growth of the alloy during the extrusion process, resulting in grain refinement of the alloy, which reduces corrosion rate compared to the MZC alloy. According to research (Bakhsheshi Rad et al., 2012), ternary $\mathrm{Ca}_{2} \mathrm{Mg}_{6} \mathrm{Zn}_{3}$ phase behaves high standard electrode potential in $\mathrm{Ca}_{2} \mathrm{Mg}_{6} \mathrm{Zn}_{3}$ and $\alpha-\mathrm{Mg}$, which means that $\mathrm{Ca}_{2} \mathrm{Mg}_{6} \mathrm{Zn}_{3}$ acts as a cathode and $\alpha-\mathrm{Mg}$ acts as an anode when galvanic corrosion occurs. Comparing the yielding stages of the five alloys with the short yielding stage of the MZC alloy, it can be further determined that the dense oxide film on the surface of the alloy is mainly ternary $\mathrm{Ca}_{2} \mathrm{Mg}_{6} \mathrm{Zn}_{3}$ phase, which is consistent with the previous research (Abdel-Gawad and Shoeib, 2019).

Compared to four alloys with different Mn contents, it can be found that with the increment of Mn content, the polarization value of the alloy cathode decreases but the anode polarization value increases. It illustrates that the increase of $\mathrm{Mn}$ element
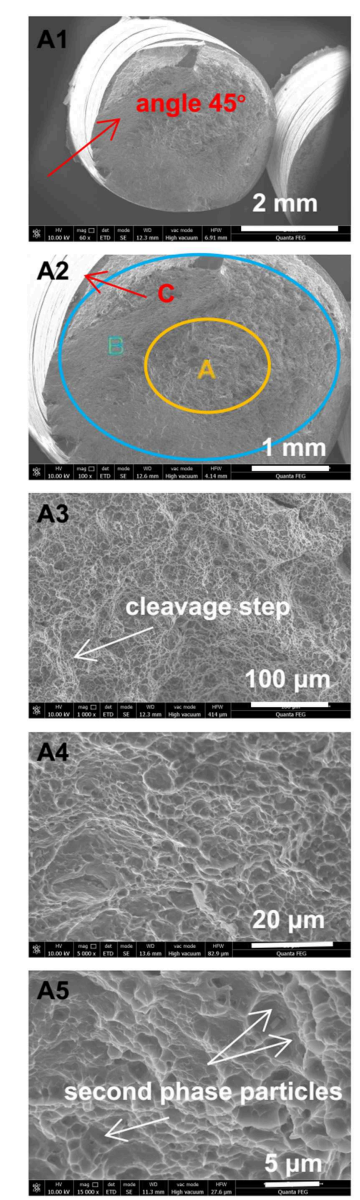
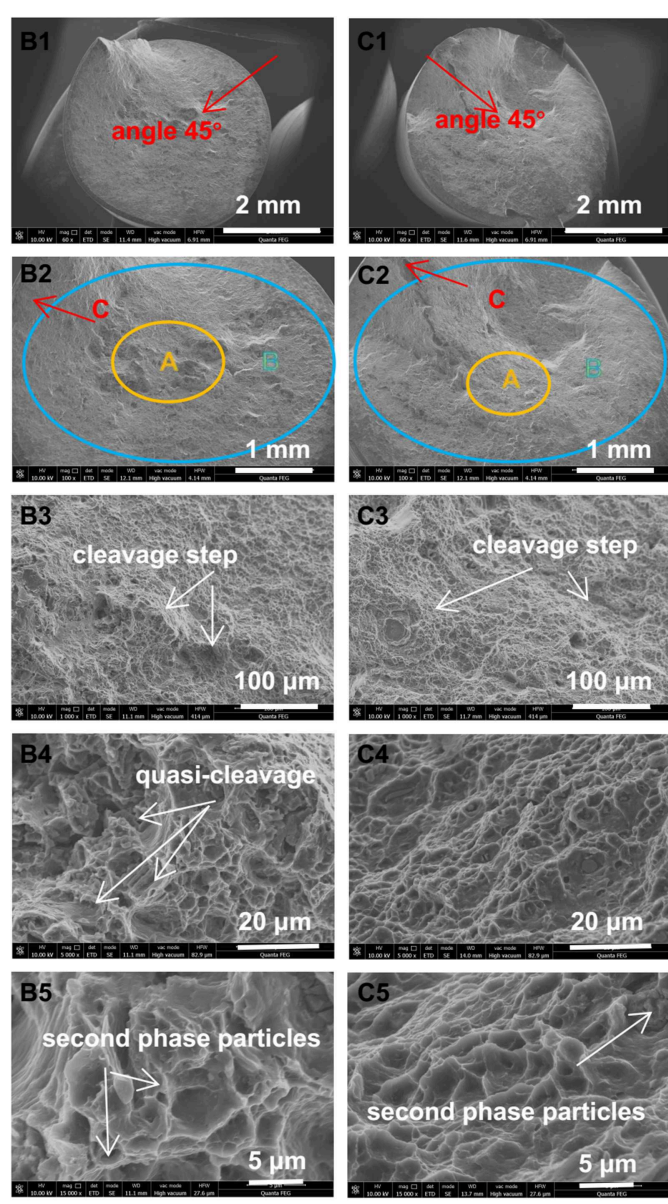
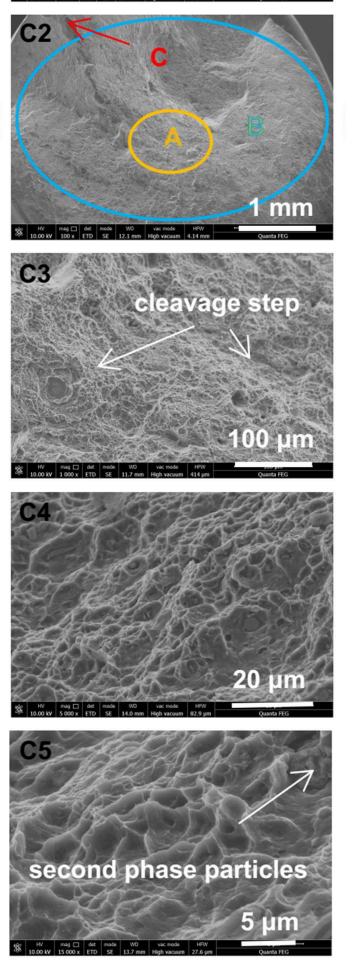
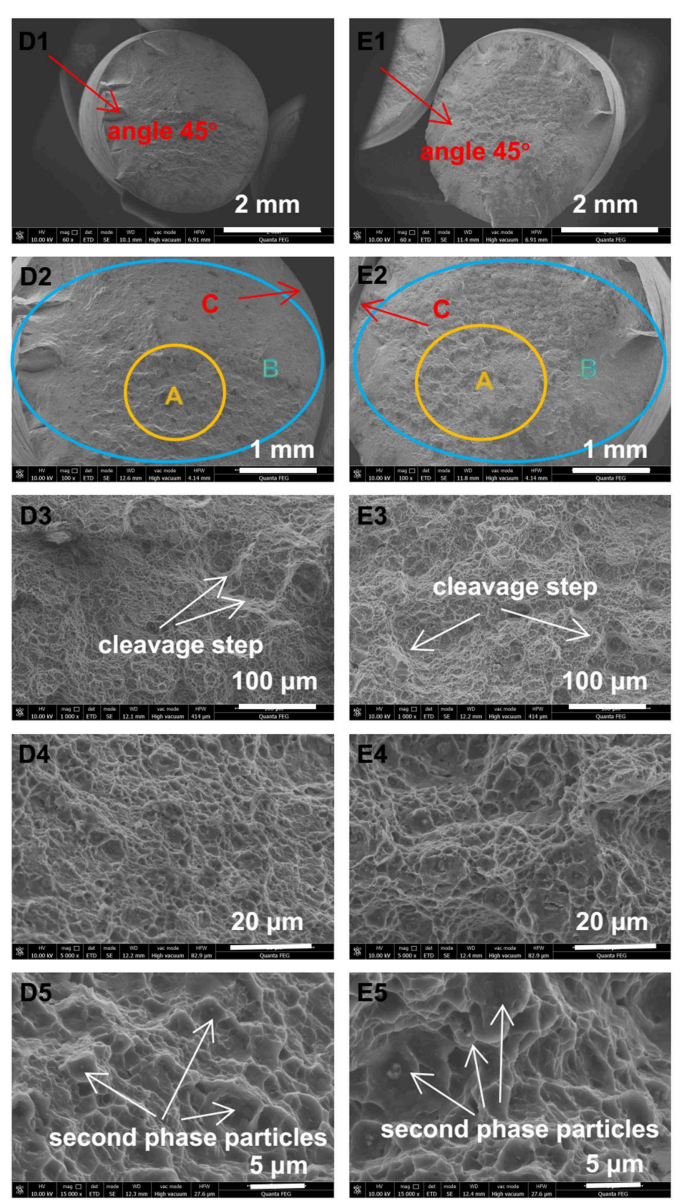

FIGURE 9 | Fracture surface morphologies of as-extruded MZC (A), MZC0.3Mn (B), MZC0.5Mn (C), MZC0.7Mn (D), and MZC0.9Mn (E) alloys. 


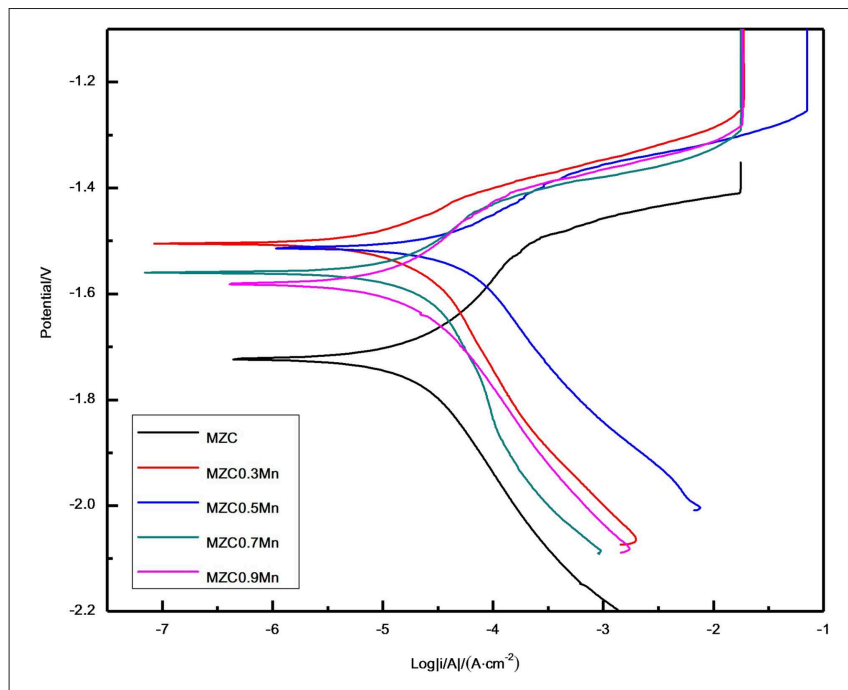

FIGURE 10 | The polarization curve of as-extruded MZC, MZC0.3Mn, MZC0.5Mn, MZC0.7Mn, and MZC0.9Mn alloys.

TABLE 2 | Electrochemical properties of as-extruded MZC, MZC0.3Mn, MZC0.5Mn, MZC0.7Mn, and MZC0.9Mn alloys.

\begin{tabular}{lccccc}
\hline Sample & $E_{\text {corr }}(\mathbf{V})$ & $I_{\text {corr }}\left(\mu \mathbf{A} / \mathbf{c m}^{2}\right)$ & $\boldsymbol{\beta}_{\mathbf{c}}(\mathbf{v} / \mathbf{d e c})$ & $\boldsymbol{\beta}_{\boldsymbol{\alpha}}(\mathbf{v} / \mathbf{d e c})$ & $\mathbf{R}_{\mathbf{p}}\left(\mathbf{k} \boldsymbol{\Omega} \cdot \mathbf{c m}^{2}\right)$ \\
\hline MZC & -1.705 & 65.68 & 0.165 & 0.134 & 0.49 \\
MZC0.3Mn & -1.502 & 30.65 & 0.239 & 0.092 & 0.94 \\
MZC0.5Mn & -1.509 & 32.25 & 0.180 & 0.119 & 0.97 \\
MZC0.7Mn & -1.556 & 48.17 & 0.167 & 0.145 & 0.70 \\
MZC0.9Mn & -1.582 & 35.03 & 0.136 & 0.176 & 0.95 \\
\hline
\end{tabular}

reduces the hydrogen evolution rate of the alloy while increasing the magnesium ion concentration.

Based on these results, the MZC0.3Mn alloy exhibited the best corrosion resistance, which may be due to the segregation of solute elements in the alloy containing Mn. As we all know, the corrosion resistance of magnesium alloys is attributed to galvanic corrosion between the second phases. In polarization curve, the degree of curve smoothness represents galvanic corrosion of the alloy. It can be seen from Figure 10 that the MZC0.3Mn alloy curve is smoother than the other three Mn-contained alloys, indicating that the MC0.3Mn alloy has less galvanic corrosion and minimal segregation. When the Mn content in the alloy is increased, excessive Mn causes segregation of the alloy to be severe and the corrosion resistance of the alloy is lowered.

Figure 11 shows the impedance spectra of as-extruded MZC, MZC0.3Mn, MZC0.5Mn, MZC0.7Mn, and MZC0.9Mn alloys. Five alloys have two capacitor rings in the high frequency region and the low frequency region. With the addition of Mn content, the diameter of the capacitor ring in the high frequency region first increases and then decreases. MZC0.5Mn alloy has the largest capacitor ring. This is consistent with the performance of the polarization curve results. The size of the capacitor ring

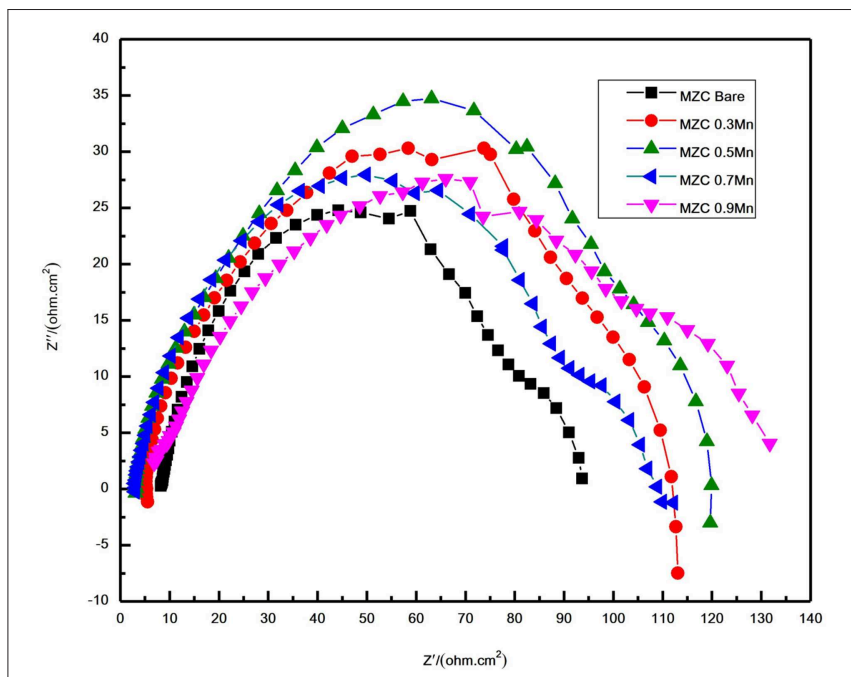

FIGURE 11 | The alternating current impedance spectra of as-extruded MZC, MZC0.3Mn, MZC0.5Mn, MZC0.7Mn, and MZCO.9Mn alloys.

represents the charge transfer suppression. The larger capacitor ring display and the more obvious charge suppression effect are observed, and the formed corrosion product film layer is more stable, which ultimately leads to better protection. The reason of MZC0.5Mn alloy with good corrosion resistance is that the minimum grain size and the dispersion of the second phase particles is fine and small, which makes the galvanic corrosion less.

\section{CONCLUSION}

In this paper, the microstructures, mechanical properties and electrochemical properties were investigated to determine the effect of alloying element Mn on the ternary MZC alloy. Comparing the microstructures of the five as-cast alloys, it can be found that the alloying element $\mathrm{Mn}$ affected the average grain size of the alloy by changing the degree of subcooling of the alloy. Compared with as-cast MZC alloy, the average grain size of as-cast MZC0.5Mn alloy was reduced by $40.1 \%$. Furthermore, it was found that the Mn element promoted the ellipsoidal second phase and the elongated second phase of the grain boundary, and also affected the size of the ellipsoidal second phase. The ellipsoidal second phase particle size $(0.8023 \mu \mathrm{m})$ of MZC0.5Mn alloy was reduced by $61.9 \%$ compared with the MZC alloy. The ellipsoidal second phase was determined by EDS to be mainly ternary $\mathrm{Ca}_{2} \mathrm{Mg}_{6} \mathrm{Zn}_{3}$ phase. The SEM of five as-extruded alloys showed that Mn element inhibited dynamic recrystallization and dynamic precipitation during extrusion, and further as heterogeneous nucleation sites promoted nucleation, resulting in the grain refinement of as-extruded alloys obviously. MZC0.5Mn alloy showed the best strength in the tensile test. The yield strength and tensile strength of MZC0.5Mn alloy were increased by 25.1 and $3.1 \%$, respectively, while the 
elongation did not decrease significantly compared to MZC alloy. The addition of $\mathrm{Mn}$ in the electrochemical experiments resulted in a denser passivation film and a lower corrosion rate. Based on the comparison of five alloys, MZC0.5Mn alloy had the best comprehensive performance and can be further optimized as a biomedical bone implant material. The further improvement of the comprehensive performance of biomedical magnesium alloys by exploring the different heat treatment processes of Mn-contained alloys can be processed in the further studies, which provide a new basis for medical bone implant materials.

\section{DATA AVAILABILITY STATEMENT}

The datasets generated for this study are available on request to the corresponding author.

\section{REFERENCES}

Abdel-Gawad, S. A., and Shoeib, M. A. (2019). Corrosion studies and microstructure of $\mathrm{Mg}-\mathrm{Zn}-\mathrm{Ca}$ alloys for biomedical applications. Surf. Interface. 14, 108-116. doi: 10.1016/j.surfin.2018.11.011

Arifin, A., Sulong, A. B., Muhamad, N., Syarif, J., and Ramli, M. I. (2014). Material processing of hydroxyapatite and titanium alloy (HA/Ti) composite as implant materials using powder metallurgy: a review. Mater. Des. 55, 167-175. doi: 10.1016/j.matdes.2013.09.045

Bakhsheshi Rad, H. R., Idris, M. H., and Kadir, M. R. A. (2012). Characterization and corrosion behavior of biodegradable $\mathrm{Mg}-\mathrm{Ca}$ and $\mathrm{Mg}-\mathrm{Ca}-\mathrm{Zn}$ implant alloys. AMM 121-126, 568-572. doi: 10.4028/www.scientific.net/AMM.121126.568

Bakhsheshi-Rad, H. R., Abdul-Kadir, M. R., Idris, M. H., and Farahany, S. J. C. S. (2012). Relationship between the corrosion behavior and the thermal characteristics and microstructure of $\mathrm{Mg}-0.5 \mathrm{Ca}-\mathrm{x} \mathrm{Zn}$ alloys. Corros. Sci. 64, 184. doi: 10.1016/j.corsci.2012.07.015

Best, S. M., Porter, A. E., Thian, E. S., and Huang, J. (2008). Bioceramics: past, present and for the future. J. Eur. Ceram. Soc. 28, 1319-1327. doi: 10.1016/j.jeurceramsoc.2007.12.001

Bian, D., Zhou, W., Deng, J., Liu, Y., Li, W., Chu, X., et al. (2017). Development of magnesium-based biodegradable metals with dietary trace element germanium as orthopaedic implant applications. Acta Biomater. 64, 422-436. doi: 10.1016/j.actbio.2017.10.004

Cho, D. H., Lee, B. W., Park, J. Y., Cho, K. M., and Park, I. M. (2017). Effect of Mn addition on corrosion properties of biodegradable $\mathrm{Mg}-4 \mathrm{Zn}-0.5 \mathrm{Ca}-\mathrm{xMn}$ alloys. J. Alloys. Compd. 695, 1166-1174. doi: 10.1016/j.jallcom.2016.10.244

Cho, D. H., Nam, J. H., Lee, B. W., Cho, K. M., and Park, I. M. (2016). Effect of Mn addition on grain refinement of biodegradable $\mathrm{Mg} 4 \mathrm{Zn} 0.5 \mathrm{Ca}$ alloy. J. Alloys Compd. 676, 466-468. doi: 10.1016/j.jallcom.2016.03.182

Du, Y. Z., Qiao, X. G., Zheng, M. Y., Wang, D. B., Wu, K., and Golovin, I. S. (2016). Effect of microalloying with $\mathrm{Ca}$ on the microstructure and mechanical properties of Mg-6 mass\%Zn alloys. Mater. Des. 98, 285-293. doi: 10.1016/j.matdes.2016.03.025

Gil-Santos, A., Marco, I., Moelans, N., Hort, N., and Van der Biest, O. (2017). Microstructure and degradation performance of biodegradable $\mathrm{Mg}$-Si-Sr implant alloys. Mater. Sci. Eng. C 71, 26-34. doi: 10.1016/j.msec.2016.09.056

Gu, X. N., Xie, X. H., Li, N., Zheng, Y. F., and Qin, L. (2012). In vitro and in vivo studies on a $\mathrm{Mg}$-Sr binary alloy system developed as a new kind of biodegradable metal. Acta Biomater. 8, 2363-2374. doi: 10.1016/j.actbio.2012.02.018

Gui, Z., Kang, Z., and Li, Y. (2018). Evolution of the microstructure and fracture characteristics of a $\mathrm{Mg}-\mathrm{Nd}-\mathrm{Zn}-\mathrm{Zr}-\mathrm{Mn}$ alloy through heat treatment and extrusion. J. Alloys Compd. 765, 470-479. doi: 10.1016/j.jallcom.2018.06.185

Guo, M. X., Du, J. Q., Zheng, C. H., Zhang, J. S., and Zhuang, L. Z. (2019). Influence of $\mathrm{Zn}$ contents on precipitation and corrosion of

\section{AUTHOR CONTRIBUTIONS}

$\mathrm{CY}, \mathrm{MC}$, and $\mathrm{YH}$ contributed conception and design of the study. $\mathrm{YH}$ organized the database and analytic result and wrote the first draft of the manuscript. CY and MC provided the experimental resources and conducted experimental supervision. YH, CY, YZ, $\mathrm{MC}$, and LW did the writing-review and editing.

\section{FUNDING}

The authors acknowledge the financial support for this work from the Joint Foundation of the National Natural Science Foundation of China (U1764254) and the National Natural Science Foundation of China (51871166), as well as Major Science and Technology projects in Tianjin (No. 15ZXQXSY00080).

Al-Mg-Si-Cu-Zn alloys for automotive applications. J. Alloys Compd., 778, 265-270. doi: 10.1016/j.jallcom.2018.11.146

Han, H. -S., Loffredo, S., Jun, I., Edwards, J., Kim, Y. -C., Seok, H. -K., et al. (2019). Current status and outlook on the clinical translation of biodegradable metals. Mater. Today 23, 59-71. doi: 10.1016/j.mattod.2018.05.018

Harkness, J. S., and Darrah, T. H. (2019). From the crust to the cortical: the geochemistry of trace elements in human bone. Geochim. Cosmochim. Acta. 249, 76-94. doi: 10.1016/j.gca.2019.01.019

He, R. G., Liu, R. Y., Chen, Q. B., Zhang, H. J., Wang, J. F., and Guo, S. F. (2018). In vitro degradation behavior and cytocompatibility of Mg-6Zn-Mn alloy. Mater. Lett. 228, 77-80. doi: 10.1016/j.matlet.2018.05.034

Ibrahim, H., Esfahani, S. N., Poorganji, B., Dean, D., and Elahinia, M. (2017). Resorbable bone fixation alloys, forming, and post-fabrication treatments. Mater. Sci. Eng. C 70, 872-888. doi: 10.1016/j.msec.2016.09.069

Jiang, H., Wang, J., Chen, M., and Liu, D. (2017). Biological activity evaluation of magnesium fluoride coated $\mathrm{Mg}-\mathrm{Zn}-\mathrm{Zr}$ alloy in vivo. Mater. Sci. Eng. C, 75, 1068-1074. doi: 10.1016/j.msec.2017.03.019

Jiang, M. G., Xu, C., Nakata, T., Yan, H., Chen, R. S., and Kamado, S. (2016). High-speed extrusion of dilute $\mathrm{Mg}$-Zn-Ca-Mn alloys and its effect on microstructure, texture and mechanical properties. Mater. Sci. Eng. A 678, 329-338. doi: 10.1016/j.msea.2016.10.007

Jin, W., Wang, G., Qasim, A. M., Mo, S., Ruan, Q., Zhou, H., et al. (2019). Corrosion protection and enhanced biocompatibility of biomedical Mg-Y-RE alloy coated with tin dioxide. Surf. Coat. Technol. 357, 79-82. doi: 10.1016/j.surfcoat.2018.10.005

Kannan, M. B., and Raman, R. K. (2008). In vitro degradation and mechanical integrity of calcium-containing magnesium alloys in modified-simulated body fluid. Biomaterials. 29, 2307-2314. doi: 10.1016/j.biomaterials.2008.02.003

Li, N., and Zheng, Y. (2013). Novel magnesium alloys developed for biomedical application: a review. J. Mater. Sci. Technol. 29, 489-502. doi: 10.1016/j.jmst.2013.02.005

Liao, H., Kim, J., Liu, T., Tang, A., She, J., Peng, P., Pan, F., et al. (2019). Effects of $\mathrm{Mn}$ addition on the microstructures, mechanical properties and work-hardening of Mg-1Sn alloy. Mater. Sci. Eng. A 754, 778-785. doi: 10.1016/j.msea.2019.02.021

Lin, G, Chen, M. F., Zhao, Y., Sasikumar, Y., and Tie, D. (2018a). The mechanical properties and corrosion resistance of magnesium alloys with different alloying elements for bone repair. Cryst. 8:271. doi: 10.3390/cryst8070271

Lin, G., Liu, D., Chen, M., You, C., Li, Z., Wang, Y., et al. (2018b). Preparation and characterization of biodegradable $\mathrm{Mg}-\mathrm{Zn}-\mathrm{Ca} / \mathrm{MgO}$ nanocomposites for biomedical applications. Mater. Charact. 144, 120-130. doi: 10.1016/j.matchar.2018.06.028

Lou, W. B., Xue, Z. Y., and Mao, W. M. (2019). Effect of heat treatment on the microstructure and micromechanical properties of the rapidly solidified Mg61.7Zn34Gd4.3 alloy containing icosahedral phase, Int. J. Miner. Metall. Mater. 26, 869-877. doi: 10.1007/s12613-019-1799-4 
Lutz, J., and Mändl, S. (2010). Reduced tribocorrosion of CoCr alloys in simulated body fluid after nitrogen insertion. Surf. Coat. Technol. 204, 3043-3046. doi: 10.1016/j.surfcoat.2010.01.048

Oh-ishi, K., Watanabe, R., Mendis, C. L., and Hono, K. (2009). Age-hardening response of $\mathrm{Mg}-0.3 \mathrm{at} . \% \mathrm{Ca}$ alloys with different $\mathrm{Zn}$ contents. Mater. Sci. Eng. A 526, 177-184. doi: 10.1016/j.msea.2009.07.027

Prins, J., Donders, J. C. E., Helfet, D. L., Wellman, D. S., Klinger, C. E., Redko, M., et al. (2018). Periprosthetic femoral nonunions treated with internal fixation and bone grafting. Injury 49, 2296-2301. doi: 10.1016/j.injury.2018.10.019

Seong, J. W., and Kim, W. J. (2015). Development of biodegradable Mg-Ca alloy sheets with enhanced strength and corrosion properties through the refinement and uniform dispersion of the $\mathrm{Mg}(2)$ Ca phase by high-ratio differential speed rolling. Acta Biomater. 11, 531-542. doi: 10.1016/j.actbio.2014.09.029

Tian, P., and Liu, X. (2015). Surface modification of biodegradable magnesium and its alloys for biomedical applications, Regen Biomater., 2, 136-151. doi: 10.1093/rb/rbu013

Witte, F. (2015). Reprint of: the history of biodegradable magnesium implants: a review. Acta Biomater. 23, S28-S40. doi: 10.1016/j.actbio.2015.07.017

Yandong, Y., Shuzhen, K., Teng, P., Jie, L., and Caixia, L. (2015). Effects of $\mathrm{Mn}$ addition on the microstructure and mechanical properties of As-cast and heat-treated Mg-Zn-Ca bio-magnesium alloy. Metal. Micro. Anal. 4, 381-391. doi: 10.1007/s13632-015-0224-2

Yin, P., Li, N. F., Lei, T., Liu, L., and Ouyang, C. (2013). Effects of $\mathrm{Ca}$ on microstructure, mechanical and corrosion properties and biocompatibility of Mg-Zn-Ca alloys. J. Mater. Sci. Mater Med. 24, 1367-1373. doi: 10.1007/s10856-013-4856-y

Zhang, B., Hou, Y. L., Wang, X. D., Wang, Y., and Geng, L. (2011). Mechanical properties, degradation performance and cytotoxicity of $\mathrm{Mg}$ Zn-Ca biomedical alloys with different compositions. Mater. Sci. Eng. C 3, 1667-1673. doi: 10.1016/j.msec.2011.07.015

Zheng, Y. F., Gu, X. N., and Witte, F. (2014). Biodegradable metals. Mater. Sci. Eng. $R$ 77, 1-34. doi: 10.1016/j.mser.2014.01.001

Zhou, W. R., Zheng, Y. F., Leeflang, M. A., and Zhou, J. (2013). Mechanical property, biocorrosion and in vitro biocompatibility evaluations of $\mathrm{Mg}$ - $\mathrm{Li}$ (Al)-(RE) alloys for future cardiovascular stent application. Acta. Biomater. 9, 8488-8498. doi: 10.1016/j.actbio.2013.01.032

Conflict of Interest: The authors declare that the research was conducted in the absence of any commercial or financial relationships that could be construed as a potential conflict of interest.

Copyright (C) 2019 Han, You, Zhao, Chen and Wang. This is an open-access article distributed under the terms of the Creative Commons Attribution License (CC BY). The use, distribution or reproduction in other forums is permitted, provided the original author(s) and the copyright owner(s) are credited and that the original publication in this journal is cited, in accordance with accepted academic practice. No use, distribution or reproduction is permitted which does not comply with these terms. 